\title{
A review of the preparation and properties of carbon nanotubes-reinforced polymer compositess
}

\author{
Fan-Long Jin ${ }^{1, \star}$ and Soo-Jin Park ${ }^{2, \star}$ \\ ${ }^{1}$ School of Chemical and Materials Engineering, Jilin Institute of Chemical Technology, Jilin City 132022, China \\ ${ }^{2}$ Department of Chemistry, Inha University, Incheon 402-751, Korea
}

\author{
Article Info \\ Received 19 February 2011 \\ Accepted 21 March 2011 \\ *Corresponding Author \\ ${ }^{1}$ E-mail: jinfanlong@gmail.com \\ ${ }^{2}$ E-mail: sjpark@inha.ac.kr
}

\section{Open Access}

DOI: 10.5714/CL.2011.12.2.057

This is an Open Access article distributed under the terms of the Creative Commons Attribution Non-Commercial License (http://creativecommons.org/licenses/ by-nc/3.0/) which permits unrestricted non-commercial use, distribution, and reproduction in any medium, provided the original work is properly cited.

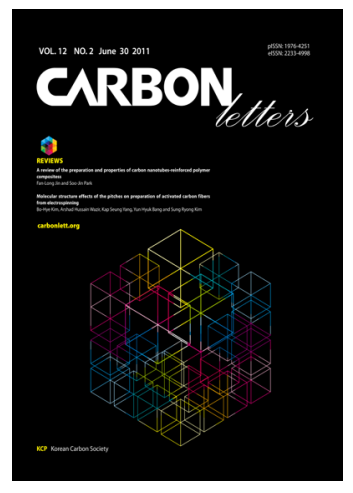

http://carbonlett.org

pISSN: $1976-4251$

elSSN: 2233-4998

Copyright $\odot$ Korean Carbon Society

\begin{abstract}
Carbon nanotubes (CNTs) have high Young's modulus, low density, and excellent electrical and thermal properties, which make them ideal fillers for polymer composites. Homogeneous dispersion of CNTs in a polymer matrix plays a crucial role in the preparation of polymer composites based on interfacial interactions between CNTs and the polymer matrix. The addition of a small amount of CNTs strongly improves the electrical, thermal, and mechanical properties of the composites. This paper aims to review the processing technology and improvement of properties of CNT-reinforced polymer composites.
\end{abstract}

Key words: carbon nanotubes, electrical properties, thermal properties, mechanical properties, polymer composites

\section{Introduction}

Carbon nanotubes (CNTs) have attracted extensive attention from researchers after their unique structure was identified in the early 1990s. Structures of CNTs are graphene sheets that are cylindrically curled. CNTs have been constructed with high length-to-diameter ratio, significantly larger than that of any other material, giving them outstanding electronic, mechanical, and thermal properties [1,2]. With these strengths, CNTs have tremendous potential for applications in many scientific and technological fields, especially for use as composite fillers in polymers to improve the mechanical, thermal and electrical properties of the resulting composites $[3,4]$.

CNTs are categorized as single-walled nanotubes (SWCNTs), double-walled CNTs (DWCNTs), triple-walled CNTs, and multi-walled nanotubes (MWNTs). The electronic properties significantly vary depending on the chirality and the number of graphene walls [5].

However, the insolubility and weak dispersibility of CNTs in common solvents and matrices have limited their applications. An effective method to improve dispersion of nanotubes is the modification of CNTs by polymers. The modification of CNTs may be divided into two categories on the basis of either non-covalent or covalent bonding between the CNTs and the polymer. Non-covalent modification of CNTs is the physical adsorption and/or wrapping of polymers to the surface of the CNTs. Covalent modification of CNTs is the covalent chemical bonding (grafting) of polymer chains to CNTs, which process dramatically improves the interfacial interactions between nanotubes and the polymer matrix. Interfacial interaction is one of the most critical issues in polymer/CNT composites [6-9].

Polymer/CNT composites can be prepared by solution processing (thermosetting and thermoplastic matrices), bulk mixing (thermoplastic matrices), melt mixing (thermosetting and thermoplastic matrices), and in situ polymerization (thermosetting and thermoplastic matrices) [6,7]. Polymer matrixes have epoxy resins, polyamide-6 (PA-6), polyacrylonitrile (PAN), polycarbonate $(\mathrm{PC})$, polyethylene $(\mathrm{PE})$, ultrahigh molecular weight polyethylene (UHMWPE), polyimide (PI), poly(methyl methacrylate) (PMMA), polypropylene (PP), 
polystyrene (PS), polyurethane (PU), poly(vinyl alcohol) (PVA) and others.

In this paper, we review the processing methods and properties, such as mechanical, thermal and electrical properties, of CNT-reinforced polymer composites.

\section{Polymer/CNT Composites}

\subsection{Epoxy/CNT composites}

Epoxy/CNT composites have been extensively investigated due to their industrial and technological applications. Epoxy/ CNT composites were fabricated using melt mixing or solution mixing methods. A typical procedure for the preparation of a composite by melt mixing method is as follows: CNTs are directly added to epoxy resin and then sonicated using an ultrasonic machine at an elevated temperature. Curing agent is added into the mixture and the mixture is degassed in a vacuum oven. Finally, mixture is injected into sample molds and is cured in an oven [10].

A typical procedure for preparation of the composites by solution mixing method is as follows: CNTs are dispersed in solution by sonication. Epoxy resin and curing agent are dissolved in acetone and mixed with the CNT suspension. This mixture is mechanically stirred and sonicated in a water bath. Acetone is removed by rotation evaporation and the mixture is cured in an oven [11].

Liu et al. [11] reported MWCNT-reinforced epoxy composites using polyethylenimine as a dispersant. Fig. 1 shows the electrical conductivity and modulus of the MWCNT-polyethylenimine/ epoxy composites. The covalently modified composites are 10 000 times more resistive than their noncovalent counterparts. Storage modulus of the composites containing covalently functionalized nanotubes is increased, relative to the noncovalent composites, due to the stronger polymer/nanotube interaction. Similar results were observed by Spitalsky et al. [12] for $\mathrm{H}_{2} \mathrm{O}_{2}$ / $\mathrm{NH}_{4} \mathrm{OH}$ mixture treated MWCNT/epoxy composites.

Bai and Allaoui [13] studied the effect of MWCNT length and aggregate size on the mechanical and electrical properties

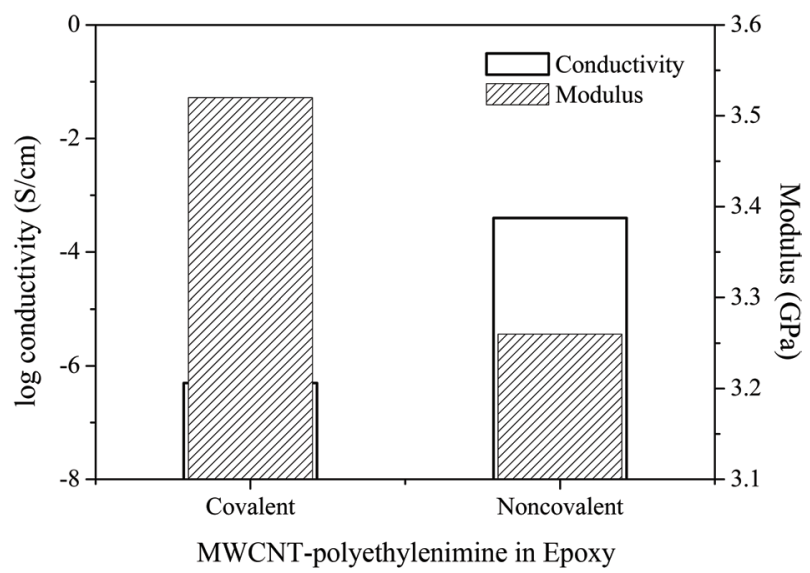

Fig. 1. Electrical conductivity and modulus of epoxy/MWNT-PEI composites [11]. MWCNT: multi-walled nanotube. of epoxy/MWCNT composites. The insulator-to-conductor transition was found to occur at $0.5 \mathrm{wt} \%$ of the as-prepared MWCNTs (Fig. 2).

Yang et al. [14] prepared amide functionalized MWCNT/ bisphenol-A epoxy resin/2-ethyl-4-methylimidazole composites. Transmission electron microscopy (TEM) showed that there was an organic thin layer on the MWCNT surface, which contributed to the homogenous dispersion of the MWCNTs in the epoxy matrix and to the improvement of the MWCNTepoxy interfacial interaction. Thus the impact strength, bending strength, and thermal conductivity of the composites were enhanced, as shown in Fig. 3. Similar results were observed by Gojny et al. [15] for different types of nanofillers-reinforced epoxy nanocomposites.

Guo et al. [10] fabricated epoxy/MWCNT nanocomposites using an ultrasonication and cast molding method. As shown in Fig. 4, the tensile strength improved with the increase of MWCNT addition. In addition, the fracture strain was also

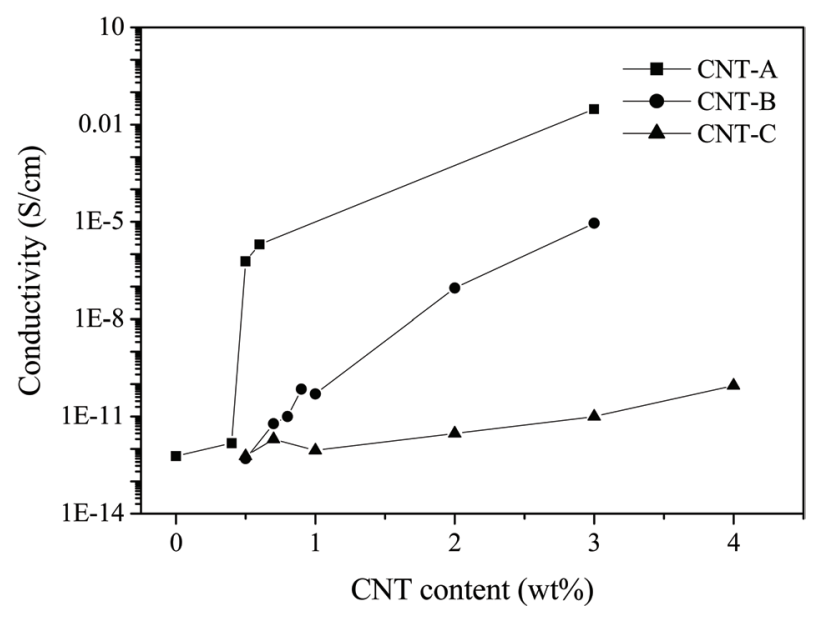

Fig. 2. Evolution of conductivity of epoxy/MWCNT composite samples as a function of nanotube concentrations for three treatments [13]. MWCNT: multi-walled carbon nanotube.

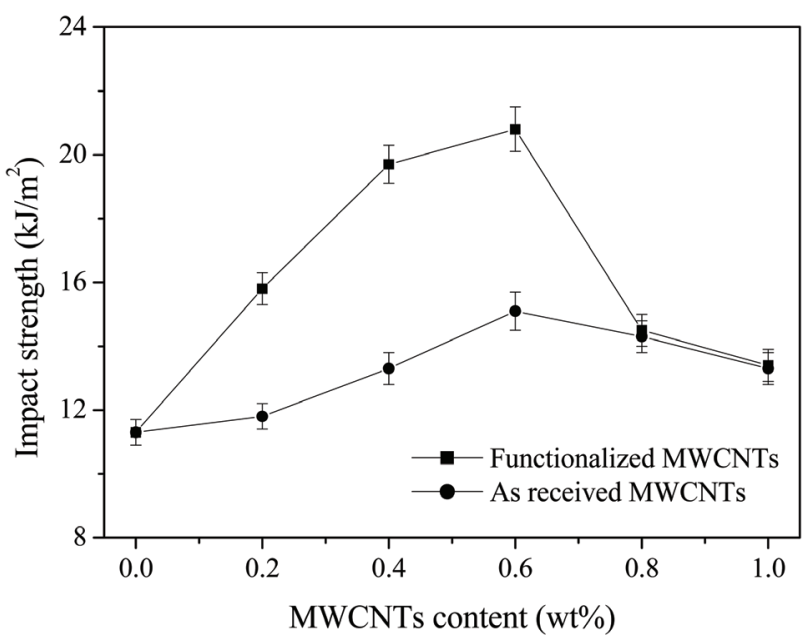

Fig. 3. Effect of MWCNT content on impact strength of epoxy/MWCNT composites [14]. MWCNT: multi-walled carbon nanotube. 


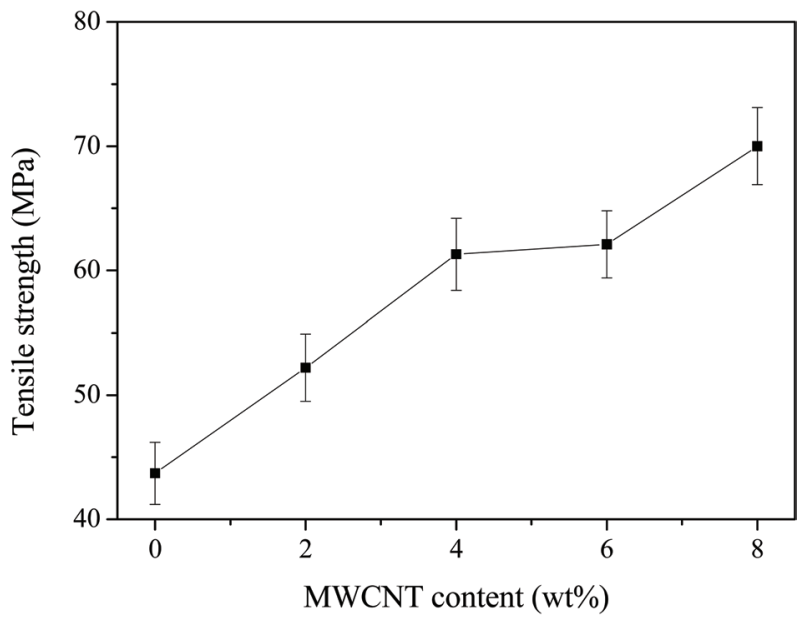

Fig. 4. Effects of MWCNT content on tensile strength of epoxy/MWCNT composites [10]. MWCNT: multi-walled carbon nanotube.

distinctly enhanced, implying that MWCNT loading not only elevated the tensile strength of the epoxy matrix, but also increased the fracture toughness.

Gong et al. [16] investigated the effect of a nonionic surfactant on the thermo-mechanical properties of epoxy/CNT composites. With the surfactant $\left(\mathrm{C}_{12} \mathrm{EO}_{8}\right)$ as the processing aid, the addition of only $1 \mathrm{wt} \% \mathrm{CNTs}$ in the composite increases the glass transition temperature $\left(\mathrm{T}_{\mathrm{g}}\right)$ from $63^{\circ} \mathrm{C}$ to $88^{\circ} \mathrm{C}$, as shown in Table 1.

Miyagawa and Drzal [17] reported on the thermo-physical properties and impact strength of diglycidyl ether of bisphenol F epoxy nanocomposites reinforced with fluorinated SWCNTs (FSWCNTs). As shown in Fig. 5, the $\mathrm{T}_{\mathrm{g}}$ decreased approximately $30^{\circ} \mathrm{C}$ with the addition of $0.2 \mathrm{wt} \%$ FSWCNTs.

Kim and Park [18] studied the effect of aminized MWCNTs (NH-MWCNTs) on the mechanical interfacial properties of epoxy nanocomposites. The mechanical interfacial properties of the nanocomposites were remarkably improved with increase of the NH-MWCNT content. Similar results were observed by Jung et al. [19] for amine epoxy adducts/thin MWCNT composite particles.

Lee et al. [20] investigated the surface treatment effect of a reinforcement filler on the dynamic mechanical properties of epoxy/MWCNT composites. The storage modulus of the epoxy/

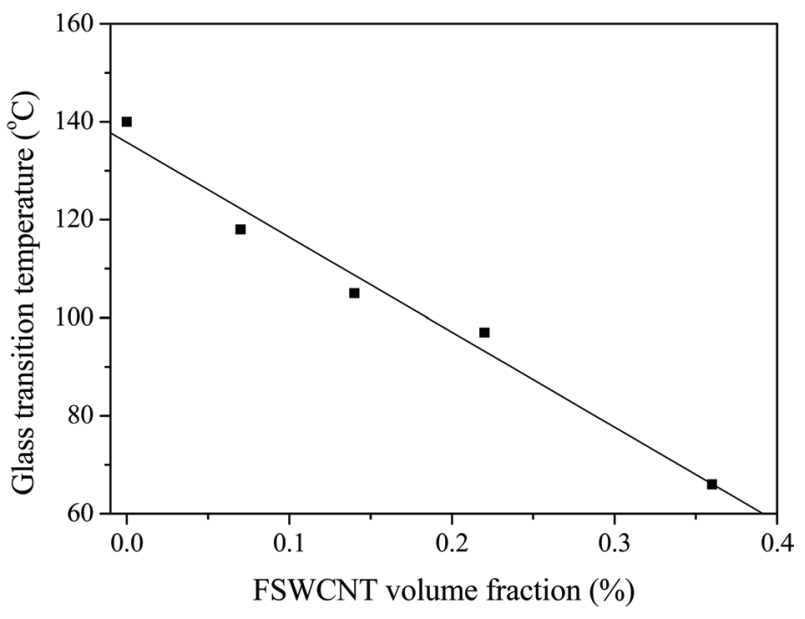

Fig. 5. Glass transition temperature of anhydride-cured epoxy nanocomposites versus FSWCNT volume content [17]. FSWCNT: fluorinated single-walled carbon nanotube.

MWCNT composite was enhanced about 1.27 times through oxyfluorination of MWCNTs at $25^{\circ} \mathrm{C}$.

\subsection{PA-6/CNT composites}

PA-6/CNT composites were prepared via a meltcompounding method or by polymerization of caprolactam. A typical procedure for preparation of the composites via the meltcompounding method is as follows: PA-6 is extruded with CNTs using a corotating twinscrew extruder at a barrel temperature of $260^{\circ} \mathrm{C}$ and a throughput of $5 \mathrm{~kg} / \mathrm{h}$. The dried pellets are injection-molded into test specimens. The molding temperature is $250-260^{\circ} \mathrm{C}$ and the mold temperature is $70^{\circ} \mathrm{C}$ [21].

A typical procedure for preparation of the composites by polymerization is as follows [22]: CNTs and caprolactam are loaded into a flask and the mixtures are sonicated at $80^{\circ} \mathrm{C}$ for $2 \mathrm{~h}$; 6 -aminocaproic acid is added to the suspension. The suspension is heated to $250^{\circ} \mathrm{C}$ with mechanical stirring under an argon atmosphere. After $6 \mathrm{~h}$, the product mixture is poured into water, and a very hard polymer precipitates. The precipitate is chopped into small pieces and washed with hot water.

Meincke et al. [21] prepared PA-6/CNT composites using a corotating twinscrew extruder. Table 2 shows the mechanical

Table 1. Storage moduli and glass transition temperatures of epoxy/CNT composites [16]

\begin{tabular}{|c|c|c|c|c|c|}
\hline \multirow{2}{*}{ Samples } & \multicolumn{3}{|c|}{ G' (GPa) } & \multicolumn{2}{|c|}{$\mathbf{T}_{\mathrm{g}}\left({ }^{\circ} \mathrm{C}\right)$} \\
\hline & $-60^{\circ} \mathrm{C}$ & $-20^{\circ} \mathrm{C}$ & $20^{\circ} \mathrm{C}$ & $\tan \delta$ & G” \\
\hline Epoxy & 1.90 & 1.65 & 1.43 & 63 & 50 \\
\hline Epoxy $+\mathrm{C}_{12} \mathrm{EO}_{8}$ & 1.53 & 1.38 & 1.20 & 62 & 47 \\
\hline Epoxy $+1 \% \mathrm{CNT}$ & 2.12 & 1.90 & 1.60 & 72 & 53 \\
\hline Epoxy $+\mathrm{C}_{12} \mathrm{EO}_{8}+1 \% \mathrm{CNT}$ & 2.54 & 2.18 & 1.80 & 88 & 64 \\
\hline
\end{tabular}

CNT: carbon nanotube. 
Table 2. Mechanical and electrical properties of PA-6/CNT composites [21]

\begin{tabular}{ccccc} 
Nanotubes (wt\%) & Young's modulus (MPa) & Elongation at break (\%) & Izod impact strength $\left(\mathbf{k J} / \mathbf{m}^{2}\right)$ & Resistivity $(\mathbf{\Omega} \mathbf{~ c m})$ \\
\hline 0 & 1970 & $105 \pm 15$ & 71 & $>10^{10}$ \\
0.9 & 2100 & $70 \pm 12$ & 60 & $>10^{10}$ \\
2.2 & 2160 & $60 \pm 15$ & 56 & $2 \times 10^{8}$ \\
2.7 & 2200 & $54 \pm 9$ & 53 & $1.5 \times 10^{5}$ \\
4.5 & 2330 & $49 \pm 13$ & $\mathrm{n} / \mathrm{a}$ & $6 \times 10^{3}$ \\
7.2 & 2510 & $44 \pm 11$ & 28 & $1.7 \times 10^{2}$ \\
\hline
\end{tabular}

PA-6: polyamide-6, CNT: carbon nanotube.

Table 3. Mechanical properties of PA-6/SWCNT composite fibers [24]

\begin{tabular}{ccccccc} 
SWCNTs content (wt\%) & 0 & 0.1 & 0.2 & 0.5 & 1.0 & 1.5 \\
\hline Tensile strength (MPa) & 40.9 & 86.0 & 92.7 & 83.4 & 83.0 & 75.1 \\
Young's modulus (MPa) & 440 & 540 & 657 & 840 & 1115 & 1200 \\
\hline
\end{tabular}

PA-6: polyamide-6, SWCNT: single-walled carbon nanotube.

Table 4. Properties of control PAN and PAN/SWCNT composite fibers [29]

\begin{tabular}{ccccc} 
Sample & Control PAN & PAN/SWCNTs & PAN/DWCNTs & PAN/MWCNTs \\
\hline Modulus (GPa) & $7.8 \pm 0.3$ & $13.6 \pm 0.5$ & $9.7 \pm 0.5$ & $10.8 \pm 0.4$ \\
Strength at break (MPa) & $244 \pm 12$ & $335 \pm 9$ & $316 \pm 15$ & $412 \pm 23$ \\
Strain to failure (\%) & $5.5 \pm 0.5$ & $9.4 \pm 0.3$ & $9.1 \pm 0.7$ & $11.4 \pm 1.2$ \\
Toughness (MPa) & $8.5 \pm 1.3$ & $20.4 \pm 0.8$ & $17.8 \pm 1.7$ & $28.3 \pm 3.3$ \\
Shrinkage at $160^{\circ} \mathrm{C}(\%)$ & 113.5 & 6.5 & 11.5 & 8.0 \\
$\mathrm{~T}_{\mathrm{g}}\left({ }^{\circ} \mathrm{C}\right)$ & 100 & 109 & 57 & 105 \\
Crystallinity $(\%)$ & 58 & 54 & 55
\end{tabular}

PAN: polyacrylonitrile, SWCNTs: single-walled carbon nanotubes, DWCNTs: double-walled CNTs, MWCNTs: multi-walled CNTs.

and electrical properties of the composites. The CNT-filled PA-6 shows an onset of electrical conductivity at low filler loadings. Tensile tests of the composites show a significant increase of $27 \%$ in the Young's modulus. Similar results were observed by $\mathrm{Xia}$ et al. [23] for PA-6/CNT composites.

Gao et al. [22,24] reported a chemical processing technology that allows the continuous spinning of PA-6/SWCNT fibers by in situ polymerization of caprolactam in the presence of amidefunctionalized SWCNTs. The number of grafted PA-6 chains that are attached to the SWCNTs can be adjusted by controlling the concentration of the initiator. As shown in Table 3, the Young's modulus, tensile strength, and thermal stability of the composite fibers produced by this process are significantly improved. Similar results were observed by Zhao et al. [25] and Shao et al. [26] for polymer-encapsulated and cut MWCNT-reinforced PA-6 composites.

Liu et al. [27] prepared PA-6/MWCNTs nanocomposites with different MWCNT loadings by a simple melt-compounding approach. Compared with the values for neat PA-6, the elastic modulus and yield strength of the composite are greatly improved by about $214 \%$ and $162 \%$, respectively, with the incorporation of only $2 \mathrm{wt} \%$ MWCNTs. Similar results were observed by Zhang et al. [28] for PA-6/MWCNT nanocomposites.

\subsection{PAN/CNTs composites}

A typical procedure for preparation of PAN/CNT composites is as follows [29]: PAN is dissolved in the stable suspension of CNTs in solvent. The PAN/CNT solutions are spun at room temperature by spinning system.

Chae et al. [29] spun PAN/CNTs composite fibers from monomer solutions and MWCNTs. Table 4 shows the properties of the fibers. The maximum increase in modulus and reduction in thermal shrinkage were observed in the SWCNT containing composites, and the maximum improvement in tensile strength, strain to failure and work of rupture were observed in the MWNTs containing composites.

Hou et al. [30] prepared well-aligned PAN/MWCNT 
Table 5. Mechanical properties of PAN/MWCNT composite nanofiber sheets [30]

\begin{tabular}{cccc} 
CNT content (\%) & Elongation at break (\%) & Tensile module (GPa) & Tensile strength (MPa) \\
\hline 0 & 10.7 & 1.8 & 45.7 \\
2 & 9.8 & 2.0 & 62.9 \\
5 & 2.5 & 3.1 & 80.0 \\
10 & 1.3 & 3.7 & 48.6 \\
20 & 0.9 & 4.4 & 37.1 \\
\hline
\end{tabular}

PAN: polyacrylonitrile, MWCNT: multi-walled carbon nanotube.

Table 6. Tensile and electrical properties of PC nanocomposite fibers based on MWCNTs and SWCNTs [32]

\begin{tabular}{|c|c|c|c|}
\hline CNTs (wt\%) & Modulus (GPa) & Yield strength (MPa) & Elongation at break $(\%)$ \\
\hline Pure PC & $1.82 \pm 0.11$ & $43.0 \pm 2.5$ & $>140$ \\
\hline $1 \mathrm{wt} \% \mathrm{MWCNT}$ & $2.20 \pm 0.21$ & $52.8 \pm 1.4$ & $>140$ \\
\hline $3 \mathrm{wt} \%$ MWCNT & $2.54 \pm 0.50$ & $60.1 \pm 2.1$ & $80 \pm 23$ \\
\hline $5 \mathrm{wt} \%$ MWCNT & $3.12 \pm 0.20$ & $63.9 \pm 3.4$ & $47 \pm 8$ \\
\hline $1 \mathrm{wt} \% \mathrm{SWCNT}$ & $2.20 \pm 0.11$ & $54.3 \pm 2.0$ & $>140$ \\
\hline $3 \mathrm{wt} \%$ SWCNT & $2.41 \pm 0.15$ & $53.4 \pm 2.2$ & $139 \pm 8$ \\
\hline $5 \mathrm{wt} \% \mathrm{SWCNT}$ & $2.77 \pm 0.12$ & $56.4 \pm 1.6$ & $96 \pm 8$ \\
\hline
\end{tabular}

PC: polycarbonate, MWCNTs: multi-walled carbon nanotubes, SWCNTs: single-walled CNTs.

composite nanofiber sheets by electrospinning an MWCNTsuspended solution of PAN. TEM observation showed that the MWCNTs were parallel and oriented along the axes of the nanofibers. The mechanical properties of the composite nanofibers were significantly increased with the increase of MWCNT content, as shown in Table 5. Similar results were observed by Chae et al. [31] for PAN/SWCNT fibers.

\subsection{PC/CNT composites}

PC/CNT composites with different loadings of CNTs were prepared by solution blending. A typical procedure is as follows [32]: a dispersion of CNTs in solvent is sonicated for $1 \mathrm{~h}$. The dispersed solution is then added to a PC solution. The mixture is sonicated for an additional $10 \mathrm{~min}$ and precipitated in excess methanol. The precipitate is dried under vacuum. PC/CNT films are prepared by solution casting.

Fornes et al. [32] prepared PC fibers based on SWCNTs and MWCNTs by first dispersing the nanotubes via solvent blending and/or melt extrusion followed by melt spinning. TEM results reveal that MWCNTs more readily disperse within the PC matrix and have higher aspect ratios than do SWCNT. As shown in Table 6, MWCNTs provide greater stiffness and strength than do SWCNTs. Similar results were observed by Singh et al. [33] for PC/SWCNT composites.

Kim and Jo [34] synthesized poly(3-hexylthiophene)-gpolycaprolactones (P3HT-g-PCLs) with different degrees of polymerization and used the resulting material as a compatibilizer for PC/MWCNT composites. As shown in Table 7, the electrical

\begin{tabular}{|c|c|c|}
\hline Sample & $\begin{array}{c}\text { MWCNT content } \\
(w t \%)\end{array}$ & $\begin{array}{c}\text { Conductivity } \\
\text { (S/cm) }\end{array}$ \\
\hline Neat PC & - & $10^{-15}$ \\
\hline PC/MWCNT & 1 & $10^{-15}$ \\
\hline $\mathrm{PC} / \mathrm{MWCNT} / \mathrm{C} 30$ & 1 & $5.8 \times 10^{-2}$ \\
\hline PC/MWCNT/C30 & 5 & $6.4 \times 10^{-1}$ \\
\hline PC/MWCNT/C50 & 1 & $8.8 \times 10^{-4}$ \\
\hline $\mathrm{PC} / \mathrm{MWCNT} / \mathrm{C} 50$ & 5 & $3.5 \times 10^{-1}$ \\
\hline
\end{tabular}

$\mathrm{Mn}$ of $\mathrm{C} 30$ and $\mathrm{C50}$ is 3100 and 48000 , respectively. PC: polycarbonate, MWCNTs: multi-walled carbon nanotubes, P3HT-gPCL: poly(3-hexylthiophene)-g-polycaprolactone.

properties of PC/MWCNT composites are dramatically improved when a small amount of P3HT-g-PCL is added to PC/ MWCNT composites.

\subsection{PE/CNT composites}

A typical procedure for the preparation of PE/CNT composites using screw extrusion and injection technique is as follows [35]: CNTs are added to a solvent and sonicated for $1 \mathrm{~h}$. The CNTs are dried in a vacuum oven and then broken into small pieces and mixed with PE. The mixture obtained is extruded with a co-rotating twin-screw compounding extruder. Finally, the composite is dried in an oven. 


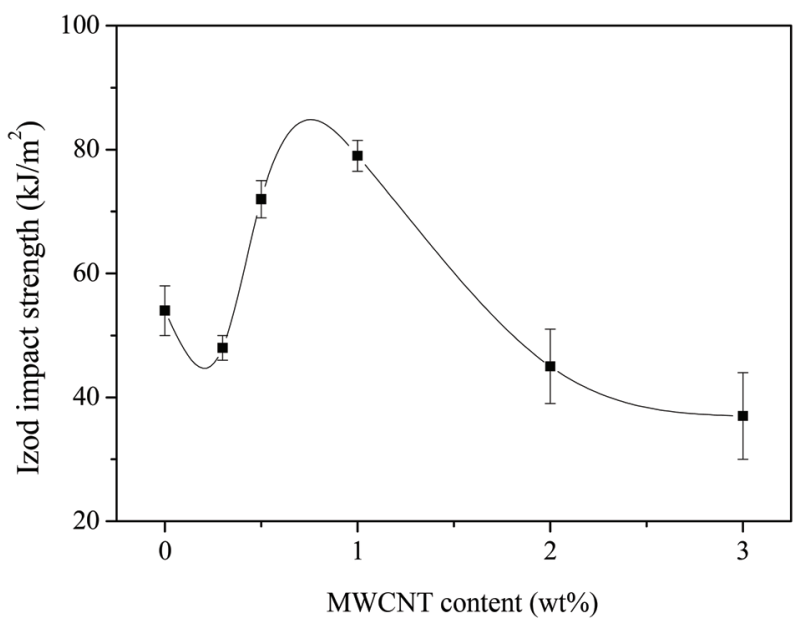

Fig. 6. Change of Izod impact strength of HDPE/MWCNT composites [35]. HDPE: high density polyethylene, MWCNT: multi-walled carbon nanotube.

Table 8. Mechanical properties of HDPE/CNT nanocomposites [36]

\begin{tabular}{cccc}
$\begin{array}{c}\text { CNT } \\
\text { content } \\
\text { (vol\%) }\end{array}$ & $\begin{array}{c}\text { Young's } \\
\text { modulus (GPa) }\end{array}$ & $\begin{array}{c}\text { Strain at } \\
\text { fracture (\%) }\end{array}$ & $\begin{array}{c}\text { Toughness } \\
(\mathbf{J})\end{array}$ \\
\hline 0.00 & 1.095 & 863.4 & 634.53 \\
0.11 & 1.169 & 948.5 & 743.35 \\
0.22 & 1.228 & 978.5 & 756.24 \\
0.33 & 1.287 & 1020.4 & 776.27 \\
0.44 & 1.338 & 1069 & 842.47 \\
\hline
\end{tabular}

CNT: carbon nanotube, HDPE: high density polyethylene.

Zou et al. [35] fabricated high density PE (HDPE)/MWCNT composites using screw extrusion and injection technique. Fig. 6 shows the Izod impact strength of the composites. At a critical MWCNT concentration of around $1 \mathrm{wt} \%$, the HDPE/MWCNT composites show much improved mechanical properties.

Kanagaraj et al. [36] reported HDPE reinforced with CNTs using injection molding. As shown in Table 8, a considerable improvement in the mechanical properties of the composites can be observed when the volume fraction of CNTs is increased. The composite reinforcement shows a good load transfer effect and interface link between CNTs and HDPE. Similar results were observed by Tang et al. [37] for HDPE/MWCNT composite films.

Xiao et al. [38] investigated the mechanical and rheological properties of low density PE (LDPE) composites reinforced by MWCNTs. The Young's modulus and tensile strength of the composites can increase by $89 \%$ and $56 \%$, respectively, when the nanotube loading reaches $10 \mathrm{wt} \%$.

Tong et al. [39] reported PE-modified SWCNTs by in situ Ziegler-Natta polymerization. The yield strength, tensile strength and modulus, strain at break, and fracture energy of the $\mathrm{PE} /$ modified-SWCNT/ composites were improved by 25,15 , 25,21 , and $38 \%$ in comparison with those values for PE/raw-

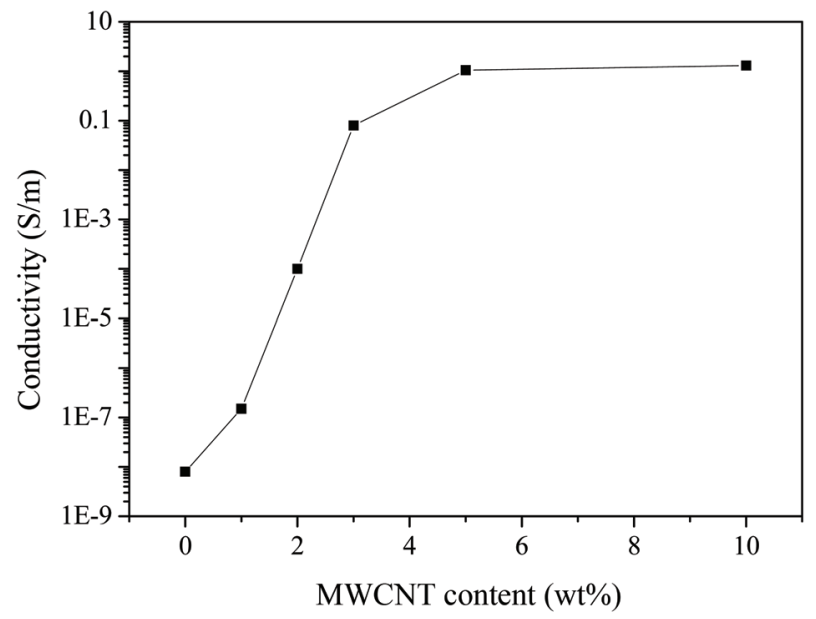

Fig. 7. Electrical conductivity of LLDPE/CNT composites as function of MWCNT content [40]. LLDPE: linear low density polyethylene, MWCNT: multi-walled carbon nanotube.

Table 9. Mechanical properties of UHMWPE fiber and UHMWPE/

MWNT composite fibers [42]

\begin{tabular}{cccc}
$\begin{array}{c}\text { MWNTs } \\
\text { content } \\
\text { (wt\%) }\end{array}$ & $\begin{array}{c}\text { Tensile } \\
\text { strength } \\
\text { (cN/dtex) }\end{array}$ & $\begin{array}{c}\text { Elongation at } \\
\text { break (\%) }\end{array}$ & $\begin{array}{c}\text { Yang's } \\
\text { modulus } \\
\text { (cN/dtex) }\end{array}$ \\
\hline 0 & 27.36 & 4.48 & 847.32 \\
0.25 & 28.44 & 4.55 & 897.23 \\
1 & 29.79 & 4.42 & 966.96 \\
2 & 29.64 & 4.24 & 959.51 \\
3 & 29.18 & 4.19 & 894.48 \\
\hline
\end{tabular}

UHMWPE: ultrahigh molecular weight polyethylene, MWCNT: multiwalled nanotube.

\section{SWCNT composites.}

Gorrasi et al. [40] prepared PE/CNT composites using high energy ball milling. The thermal degradation was already significantly delayed with $1-2 \mathrm{wt} \%$ CNTs. The resulting mechanical properties were greatly improved for low filler content. The electrical measurements showed a percolation threshold in the range 1-3 wt $\%$ CNTs, as shown in Fig. 7.

\subsection{UHMWPE/CNT composites}

A typical procedure for the preparation of UHMWPE/CNT composite films is as follows [41]: CNTs are dispersed in xylene by magnetic stirring and ultrasonic vibration. The mixture is poured into the UHMWPE-xylene solution and refluxed for 1 h. The UHMWPE/CNT films are prepared by solution casting.

A typical procedure for preparation of UHMWPE/CNT composite fibers is as follows [42]: The mixture of olefin and CNTs is ultrasonicated until the CNTs are uniformly dispersed. Then, the UHMWPE powder is added to the mixture. The mixture is then heated until a homogeneous UHMWPE solution is obtained. The solution is subsequently spun into gel fibers by gel spinning. 


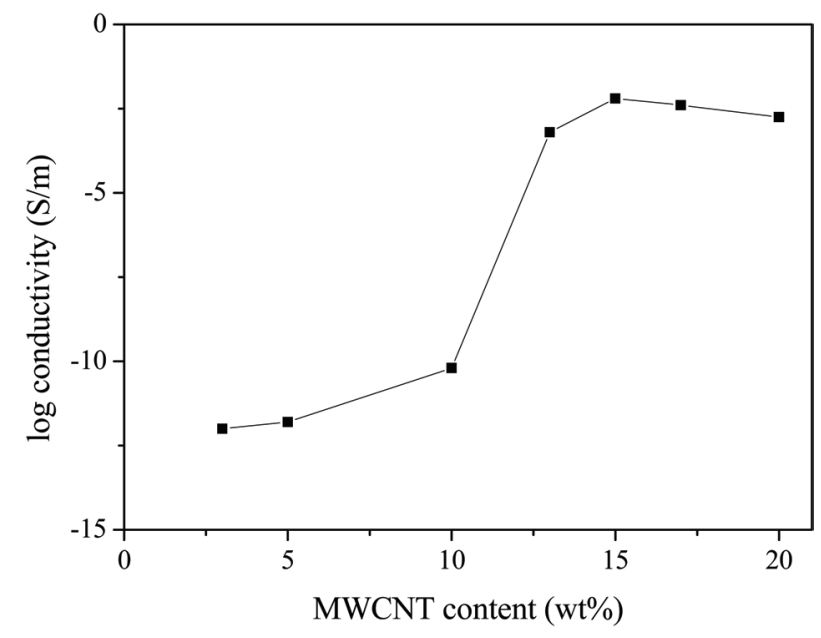

Fig. 8. Electric conductivity of UHMWPE-based composites as a function of MWCNT content [41]. UHMWPE: ultrahigh molecular weight polyethylene, MWCNT: multi-walled carbon nanotube.

Wang et al. [42] prepared UHMWPE/CNT composite fibers by gel spinning. The results showed that a good interaction between functionalized CNTs and UHMWPE matrix was established. Table 9 shows the mechanical properties of the fibers. The mechanical and thermal properties of the UHMWPE/ CNT fibers were improved compared with those properties for pure UHMWPE fiber. Similar results were observed by Ruan et al. $[43,44]$ for UHMWPE/MWCNT films.

Bin et al. [41] prepared UHMWPE/MWCNT composites by gelation/crystallization from solution. As shown in Fig. 8, the electric conductivity was $10^{-3} \mathrm{~S} / \mathrm{cm}$, which qualifies these materials as conductive; the Young's modulus reached $58 \mathrm{GPa}$ at room temperature.

\subsection{PI/CNT composites}

PI/CNT composites were prepared by melt blending, in situ polymerization and thermal imidization. A typical procedure for preparation of the composites by melt blending is as follows [45]: PI and CNTs are melt mixed at $325^{\circ} \mathrm{C}$ for $1 \mathrm{~h}$ using a Brabender. After melt mixing, the resulting material is ground through a $1 \mathrm{~mm}$ mesh screen and extruded with a single screw extruder. Extrudates from the first pass are ground and re-extruded two more times to obtain the fibers.

A typical procedure for the preparation of composites by in situ polymerization and thermal imidization is as follows [46]: CNTs/imide oligomer mixtures containing CNTs are prepared using a mechanical blender for several minutes. The CNT/imide oligomer mixture is melted at $320^{\circ} \mathrm{C}$ for $10 \mathrm{~min}$ on a steel plate in a hot press, and then cured at $370^{\circ} \mathrm{C}$ for $1 \mathrm{~h}$.

Ogasawara et al. [46] prepared PI/MWCNT composites by in situ polymerization and thermal imidization. Table 10 shows the properties of the composites. The $\mathrm{T}_{\mathrm{g}}$, elastic modulus and the yield strength were increased with the incorporation of MWCNTs. Similar results were observed by Yu et al. [47] for individual and small bundle CNT-reinforced PI composites.

Siochi et al. [45] prepared PI/SWCNT nanocomposite fibers by melt processing. SWCNT alignment in the fiber

\begin{tabular}{cccc}
\multicolumn{4}{c}{ Table 10. Properties of PI/MWCNT composites [46] } \\
CNT (wt\%) & $\left.\mathbf{T}_{\mathbf{g}} \mathbf{(}^{\circ} \mathbf{C}\right)$ & $\begin{array}{c}\text { Elastic } \\
\text { modulus } \\
\mathbf{( G P a )}\end{array}$ & $\begin{array}{c}\text { Yield } \\
\text { strength } \\
\text { (MPa) }\end{array}$ \\
\hline 0 & 335 & 2.84 & 69.8 \\
3.3 & 339 & 3.07 & 80.5 \\
7.7 & 350 & 3.28 & 84.6 \\
14.3 & 357 & 3.90 & 92.6 \\
\hline
\end{tabular}

PI: polyimide, MWCNT: multi-walled carbon nanotube.

Table 11. Tensile properties of PI/SWCNT nanocomposite fibers [45]

\begin{tabular}{ccccc}
$\begin{array}{c}\text { SWCNT } \\
\text { content } \\
(\mathbf{w t} \%)\end{array}$ & $\begin{array}{c}\text { Tensile } \\
\text { modulus } \\
(\mathbf{G P a})\end{array}$ & $\begin{array}{c}\text { Elongation } \\
\mathbf{( \% )}\end{array}$ & $\begin{array}{c}\text { Toughness } \\
\left(\mathbf{m J} / \mathbf{m m}^{\mathbf{3}}\right)\end{array}$ & $\begin{array}{c}\text { Yield } \\
\text { stress } \\
\mathbf{( M P a )}\end{array}$ \\
\hline 0 & 2.2 & 175 & 123 & 74 \\
0.1 & 2.6 & 125 & 100 & 86 \\
0.3 & 2.8 & 110 & 92 & 94 \\
1.0 & 3.2 & 20 & 6 & 100 \\
\hline
\end{tabular}

PI: polyimide, SWCNT: single-walled carbon nanotube.

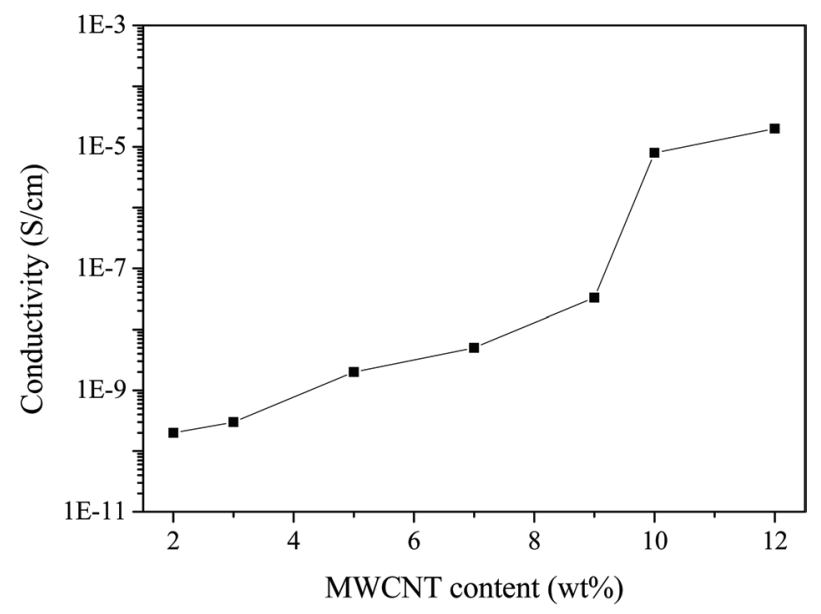

Fig. 9. Variation of electrical conductivity of PI/MWNTs nanocomposites with MWCNT content (10 kHz) [49]. PI: polyimide, MWNT: multi-walled nanotube; MWCNT: multi-walled carbon nanotube.

direction was induced by the shear forces present during the melt extrusion and fiber drawing processes. This alignment resulted in significantly higher tensile moduli and yield stress in the PI/SWCNT nanocomposite fibers relative to those values for unoriented nanocomposite films having the same SWCNT concentration, as shown in Table 11.

Liu et al. [48] prepared polyetherimide (PEI)/MWCNT nanocomposite films by casting and imidization. With the addition of $1 \mathrm{wt} \%$ MWCNTs, the $\mathrm{T}_{\mathrm{g}}$ of PEI increases by about $10^{\circ} \mathrm{C}$ and the elastic moduli of the nanocomposites significantly improved by about $250 \%$, comparable to that of the matrix.

Zhu et al. [49] prepared PI/MWCNT nanocomposite films 
by casting and thermal imidization. As shown in Fig. 9, the electrical properties of the nanocomposite films were greatly improved with the incorporation of MWCNTs due to the strong interfacial interaction between the modified MWCNTs and the PI matrix. Similar results were observed by So et al. [50] and Yuen et al. [51] for PI/MWCNT nanocomposites.

\subsection{PMMA/CNT composites}

PMMA/CNT composites were prepared using melt blending and in situ polymerization. A typical procedure for preparation of the composites by melt blending method is as follows [52]: CNTs and PMMA are blended in a Mixing Molder. The resulting materials are then pressed in a hydraulic press under atmospheric pressure.

A typical procedure for preparation of composites by in situ polymerization method is as follows [53]: CNTs are dispersed in a liquid state of methyl methacrylate (MMA) monomer. An ultrasound is then applied to the CNTs dispersion. Polymerizations of MMA/CNTs are conducted using an initiator.

Jia et al. [53] prepared PMMA/CNT composites by in situ process. Table 12 shows the properties of the composites. The mechanical properties and the heat deflection temperatures of the composites rise with the increase of CNTs. The dispersion ratio of CNTs in the PMMA matrix is proportional to the reaction time of the polymerizing MMA before CNTs are added into the PMMA mixture. Similar results were observed by other researchers for PMMA/CNT composites [54-57].

Wang et al. [58] studied the dynamic mechanical behavior of PMMA/acidified MWCNT composites compatibilized with amine-terminated poly(ethylene oxide) (PEO). The miscibility between PEO and PMMA improves the interfacial adhesion between the polymer matrix and the MWCNTs, leading to an increase in the storage modulus values of the composites, as shown in Fig. 10. Similar results were observed by VelascoSantos et al. [59] for PMMA/MWCNT composites.

Seo et al. [52] prepared PMMA/MWCNT composites via in situ polymerization. The results indicate that the radical initiator (AIBN) and MWCNT increase the polymerization rate and the MWCNT diameter. Induced radicals on the MWCNT due to AIBN were found to trigger the grafting of PMMA. Moreover,

Table 12. Properties of PMMA/CNT composites [53]

\begin{tabular}{|c|c|c|c|c|}
\hline $\begin{array}{c}\text { Treated } \\
\text { CNT } \\
(w t \%)\end{array}$ & $\begin{array}{c}\text { Tensile } \\
\text { strength } \\
\text { (MPa) }\end{array}$ & $\begin{array}{c}\text { Toughness } \\
\left(\mathbf{k J} / \mathbf{m}^{2}\right)\end{array}$ & $\begin{array}{c}\text { Hardness } \\
\text { HB } \\
\left(\mathrm{kg} / \mathrm{m}^{2}\right)\end{array}$ & $\begin{array}{c}\text { Heat } \\
\text { deflection } \\
\text { temperature } \\
(\mathrm{K})\end{array}$ \\
\hline 0.0 & 54.9 & 1.34 & 19.21 & $386-388$ \\
\hline 1.0 & 58.70 & 1.45 & 26.7 & $406-408$ \\
\hline 3.0 & 66.80 & 1.47 & 26.9 & $418-420$ \\
\hline 5.0 & 71.66 & 1.49 & 27.3 & $425-427$ \\
\hline 7.0 & 71.65 & 1.49 & 28.5 & $427-429$ \\
\hline 10.0 & 47.15 & 0.86 & 28.2 & - \\
\hline
\end{tabular}

PMMA: poly(methyl methacrylate), CNT: carbon nanotube, HB: Brinell hardness number.

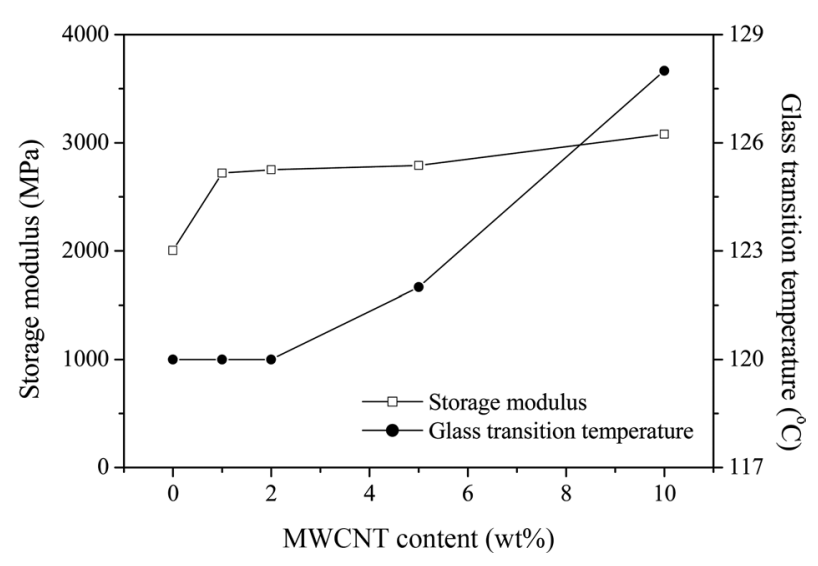

Fig. 10. Storage moduli at $40^{\circ} \mathrm{C}$ and $T_{g}$ values of PMMA/MWCNT composites [58]. PMMA: poly(methyl methacrylate), MWCNT: multi-walled carbon nanotube.

the solvent cast film showed a better nanoscopic dispersion of MWNTs, which could lead to the possibility of CNT composites in engineering applications.

Park et al. [60] prepared a PMMA/MWCNT nanocomposite by in situ polymerization of MMA dispersed with MWCNTs. The acid treated MWNTs were well dispersed in MMA with fairly good dispersion stability, while flocculation and sedimentation were observed from raw MWCNTs in MMA.

\subsection{PP/CNT composites}

A typical procedure for the preparation of $\mathrm{PP} / \mathrm{CNT}$ composites by solvent-mixing method is as follows [61]: PP is added to a solvent and dissolved by mechanical stirring. The obtained gel-like solution is poured onto aluminum foil and placed in a vacuum oven. After drying, the material is left to cool to ambient and is then broken into small pieces. The fibers are spun using an Instron capillary rheometer.

A typical procedure for preparation of the composites by melt-mixing method is as follows [62]: composites are prepared in an internal mixer, equipped with a pair of high shear rollertype rotors. The temperature of the mixing chamber is set at $190^{\circ} \mathrm{C}$ and the blending time is $15 \mathrm{~min}$. Once the polymer is molten, the appropriate percentage of CNTs is added. The obtained compounds are subject to compression at $200^{\circ} \mathrm{C}$ for $15 \mathrm{~min}$ in a Colling press.

Manchado et al. [61] investigated the dispersion of SWCNTs in isotactic PP (iPP) by shear mixing. The results indicate that the addition of low SWNT amounts led to an increase in the rate of polymer crystallization with no substantial changes in the crystalline structure. As shown in Fig. 11, the Young's modulus and tensile strength considerably increase in the presence of nanotubes. Similar results were observed by other researchers for PP/CNT composites [52,63-65].

Kearns and Shambaugh [62] reported that the strength properties of PP fibers were enhanced with SWCNTs. For a $1 \mathrm{wt} \%$ loading of nanotubes, the tensile strength of the fibers increased $40 \%$ and the modulus increased 55\%, as can be seen in Table 13 .

Grady et al. [66] reported on the nonisothermal and isothermal crystallization of PP/CNT systems. Nanotubes promoted growth 


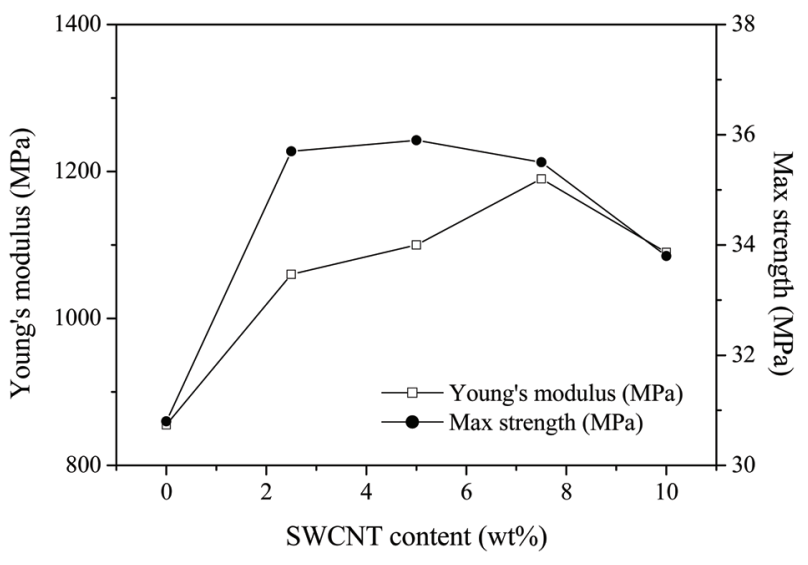

Fig. 11. Variation of Young's modulus and yield strength as a function of SWCNT content in PP/SWCNT composites [61]. PP: polypropylene, SWCNT: single-walled carbon nanotube.

Table 13. Mechanical properties of PP/SWCNT composite fibers as a function of nanotube loading [62]

\begin{tabular}{cccc}
$\begin{array}{c}\text { CNT content } \\
\text { (\%) }\end{array}$ & $\begin{array}{c}\text { Tensile } \\
\text { strength } \\
\text { (MPa) }\end{array}$ & $\begin{array}{c}\text { Modulus } \\
\text { (GPa) }\end{array}$ & $\begin{array}{c}\text { Tenacity } \\
\text { (g/den) }\end{array}$ \\
\hline 0 & 709 & 6.3 & 9.0 \\
0.5 & 838 & 9.3 & 10.6 \\
1 & 1032 & 9.8 & 13.1 \\
\hline
\end{tabular}

PP: polypropylene, SWCNT: single-walled carbon nanotube.

of the less-preferred beta form of crystalline PP at the expense of the alpha form. The rate of crystallization was substantially higher in the CNT-filled systems. The results clearly show that CNTs nucleate crystallinity in PP.

Shim and Park [67] studied the effect of glycidyl methacrylate grafted MWCNTs (GMA-MWCNTs) on the viscoelastic behaviors of PP based nanocomposites. The PP/GMA-MWCNT nanocomposites showed higher storage modulus, loss modulus, and shear viscosity compared to those values for pure PP.

Karevan et al. [68] investigated the effect of filler content, presence of interphase, and agglomerates on the effective Young's modulus of PP based nanocomposites reinforced with CNTs. It was found that the interphase has an average width of $\sim 30 \mathrm{~nm}$ and modulus in the range of 5 to $12 \mathrm{GPa}$.

\subsection{PS/CNT composites}

A typical procedure for the preparation of a PS/CNT composite is as follows [69]: CNTs are dispersed in toluene using an ultrasonic wand dismembrator. The CNT suspensions are then admixed with toluene solutions of PS to yield PS/CNT solutions. These mixtures are further homogenized in an ultrasonic bath. Thin composite films are then produced from these solutions using two different techniques, film casting and spin casting.

A typical procedure for film casting is as follows: Solution is poured into a flat-bottomed glass culture dish, and the toluene is allowed to evaporate. Thin uniform films are obtained and dried

\begin{tabular}{ccc}
\multicolumn{2}{c}{ Table 14. Properties of PS/MWCNT composite films [69] } \\
$\begin{array}{c}\text { MWCNT content } \\
\text { (vol\%) }\end{array}$ & $\begin{array}{c}\text { Elastic modulus } \\
\text { (MPa) }\end{array}$ & $\begin{array}{c}\text { Tensile strength } \\
\text { (MPa) }\end{array}$ \\
\hline 0 & $1530 \pm 110$ & $19.5 \pm 3.0$ \\
0.487 & $2100 \pm 180$ & $24.5 \pm 3$ \\
0.98 & $2730 \pm 220$ & $25.7 \pm 1.2$ \\
2.49 & $3400 \pm 190$ & $30.6 \pm 2.7$ \\
\hline
\end{tabular}

PS: polystyrene, MWCNT: multi-walled carbon nanotube.

in a vacuum oven.

A typical procedure for spin casting is as follows: PS/CNT solutions are deposited at the center of a rotating disk and spun on a Spin Coater. Thin films are formed and the films are subsequently dried in a vacuum oven.

Safadi et al. [69] reported on the basic relationships between processing conditions and the mechanical and electrical properties of MWCNT reinforced PS composites. Table 14 shows the properties of the composites. The presence of 2.5 vol\% MWCNTs approximately doubles the tensile modulus, and transforms the film from insulating to conductive.

Andrews et al. [70] investigated the dispersion of nanotubes in polymer matrices to derive new and advanced engineering materials. The nanotube concentration at which conductivity was initiated varied with the host polymer. In PP, this concentration was as low as $0.05 \mathrm{vol} \%$, while higher concentrations were required for PS, and particularly for ABS.

Xie et al. [71] prepared SWCNTs with high covalent bonding density of polymer layers by a "grafting to" approach. Only $0.06 \mathrm{wt} \%$ of SWCNTs resulted in $82 \%$ and $78 \%$ increases in tensile strength and elastic modulus of polymer composites, respectively, indicating an efficient interfacial stress transfer between SWCNTs and polymer.

\subsection{PU/CNT composites}

PU/CNT membranes were prepared by electrospinning/ electrospraying technique and sol-gel process. PU/CNT films were made using a convenient solution process. A typical procedure for preparation of the composites by in situ polymerization is as follows [72]: CNTs are dispersed in dried polyoxytetramethylene glycol via an ultrasonicator for $1 \mathrm{~h}$ at room temperature to form a suspension. Then, toluene diisocyanate is added to the suspension and reacted with the modified CNTs at $40^{\circ} \mathrm{C}$ for $1 \mathrm{~h}$. Subsequently, the system is moved immediately to an oil-bath and reacted for at $80^{\circ} \mathrm{C} 1.5 \mathrm{~h}$.

A typical procedure for preparation of composite films is as follows [73]: PU is dissolved in THF and the CNTs is added to the PU solution, with continuous stirring. The solution is then sonicated for $2 \mathrm{~h}$ in a sonic bath, followed by subsequent casting and controlled solvent evaporation. Free-standing PU/SWNT composite films are obtained by peeling them from the Teflon disk.

Koerner et al. [73] reported the addition of small amounts of MWCNT to thermoplastic elastomer produced polymer nanocomposites with high electrical conductivity, low electrical percolation, and enhancement of mechanical properties including increased modulus and yield stress, as shown in Fig. 12. 


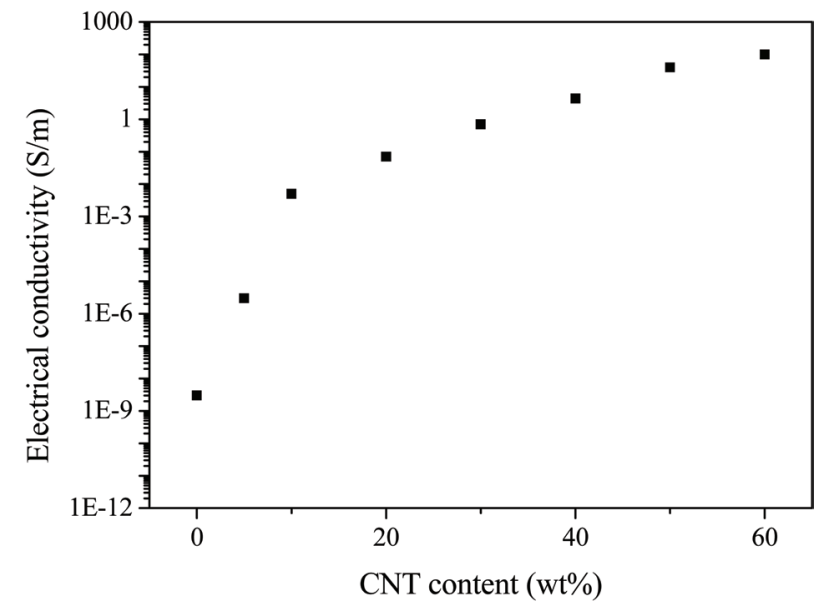

Fig. 12. DC bulk conductivity of PU/CNT composites as a function of CNT content [73]. PU: polyurethane, CNT: carbon nanotube.

\section{Table 15. Tensile properties of PU/MWNT composites [74]}

\begin{tabular}{cccc}
$\begin{array}{c}\text { MWNT } \\
\text { content (wt\%) }\end{array}$ & Strain (\%) & $\begin{array}{c}\text { Tensile } \\
\text { (MPa) }\end{array}$ & $\begin{array}{c}\text { Modulus } \\
\text { (MPa) }\end{array}$ \\
\hline 0 & $249 \pm 20$ & $22.1 \pm 2.5$ & $9.7 \pm 0.08$ \\
0.1 & $296 \pm 22$ & $24.4 \pm 3.1$ & $10.2 \pm 0.11$ \\
0.3 & $252 \pm 10$ & $26.1 \pm 1.6$ & $20.2 \pm 0.17$ \\
0.5 & $222 \pm 6$ & $35.2 \pm 2.2$ & $36.4 \pm 0.34$ \\
\hline
\end{tabular}

PU: polyurethane, MWNT: multi-walled nanotube.

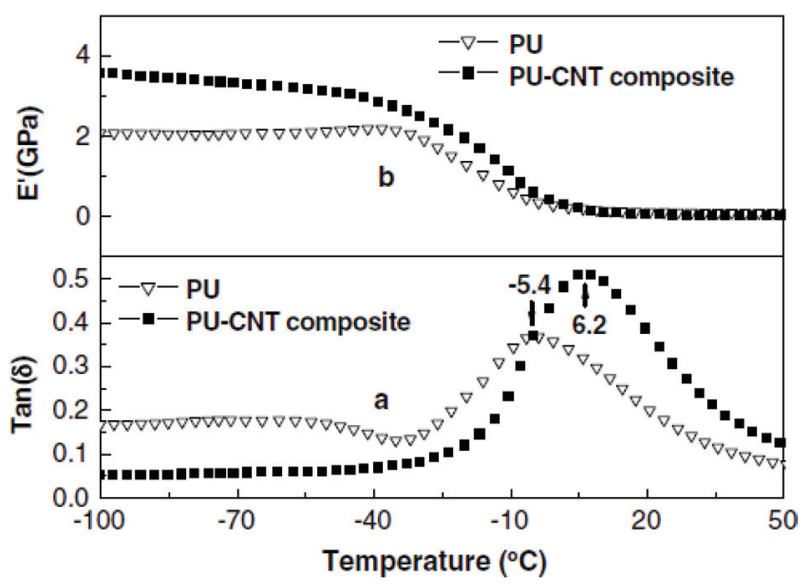

Fig. 13. Dynamic mechanical thermal analysis curves of PU/CNT composites with $2 \mathrm{wt} \% \mathrm{CNT}$ : (a) loss factors (tan $\delta$ ) and (b) storage modulus ( $\left.E^{\prime}\right)$ [72]. PU: polyurethane, CNT: carbon nanotube.

$\mathrm{Xu}$ et al. [74] prepared a series of novel self-crosslinkable PU/MWCNT composites using the sol-gel process. As shown in Table 15, a small amount of amide-functionalized MWCNT in the samples may increase the Young's modulus and tensile strength significantly, with no loss of elongation. Similar results were observed by Sen et al. [75] and Chen and Tao [76] for PU/ CNT composites.

Xiong et al. [72] synthesized a PU/amide-functionalized
Table 16. Tensile properties of PVA/CNT composite films [78]

\begin{tabular}{|c|c|c|}
\hline Sample & $\begin{array}{c}\text { Young's modulus } \\
\text { (GPa) }\end{array}$ & $\begin{array}{l}\text { Yield stress } \\
\text { (MPa) }\end{array}$ \\
\hline PVA & $4.0 \pm 0.1$ & $83 \pm 1$ \\
\hline $\begin{array}{c}\text { PVA }+2.5 \mathrm{wt} \% \\
\text { functionalized SWCNT }\end{array}$ & $5.6 \pm 0.4$ & $97 \pm 15$ \\
\hline $\begin{array}{c}\text { PVA }+5 \mathrm{wt} \% \\
\text { functionalized SWCNT }\end{array}$ & $6.2 \pm 0.1$ & $128 \pm 2$ \\
\hline $\begin{array}{l}\mathrm{PVA}+2.5 \mathrm{wt} \% \\
\text { pure } \mathrm{SWCNT}\end{array}$ & $5.4 \pm 0.4$ & $79 \pm 1$ \\
\hline
\end{tabular}

PVA: poly(vinyl alcohol), SWCNT: single-walled carbon nanotube.

MWCNT elastomer composite. As shown in Fig. 13, the $T_{g}$ of the composite was increased by about $10^{\circ} \mathrm{C}$ and its thermal stability was obviously improved, in comparison with those properties for pure PU.

Kim et al. [77] investigated the DC conductivity of PU/ MWCNT composites with a variety of oxidation conditions, surfactants, and surfactant contents. It was found that in order to enhance DC conductivity of the composites containing oxidized MWCNT, a better dispersion of MWCNT should be obtained by effective functionalities and surfactant adsorption while preserving the intrinsic geometry of the pristine MWCNT.

\subsection{PVA/CNT composites}

A typical procedure for preparation of PVA/CNT composite films is as follows [78]: a PVA polymer sample is dissolved in water to obtain a PVA solution. CNTs solution is added to the PVA solution, and the solution is stirred. The resulting solution is cast onto a glass slide and the film is dried at room temperature.

Paiva et al. [78] prepared PVA/water-soluble PVAfunctionalized CNT composites via a wet-casting method. Table 16 shows the tensile properties of the composites. The mechanical properties of the nanocomposite films were significantly improved compared to those of neat polymer film. Functionalization allowed good distribution of the nanotubes in the matrix, leading to higher film strength.

Ryan et al. [79] reported a 4.5 fold increase in the Young's modulus of PVA with the addition of CNTs. It is suggested that in PVA/CNT systems, with non-covalent bonding between the filler and the matrix, the formation of nanotube induced crystalline polymer domains is the dominant reinforcement mechanism and not stress transfer to the nanotube; the role of the nanotube lies in nucleating crystallization. Similar results were observed by other researchers for PVA/MWCNT composites [80-82].

Shaffer and Windle [83] described a successful route for the fabrication of large PVA/CNT composite films containing nanotubes. Their process should be broadly applicable to a range of nanotube materials and polymers. The densities of the composites follow a linear law of mixtures, and the electrical conductivities show typical percolation behavior, as can be seen in Fig. 14.

\section{Conclusions}

In this paper, we reviewed the preparation and properties 
of CNT-reinforced polymer composites. For a certain polymer matrix, different treatment of CNTs and processing methods were used. Homogeneous dispersion of CNTs in the polymer matrix is very important to improve the properties of the polymer composites. The electrical, thermal, and mechanical properties of the composites were significantly increased with the addition of a small amount of CNTs. CNT-reinforced polymer composites as multifunctional high-performance materials are currently of great interest for use in an extensive range of electronic, aerospace, and military applications.

\section{References}

[1] Iijima S. Helical microtubules of graphitic carbon. Nature, 354, 56 (1991). doi: 10.1038/354056a0

[2] Ajayan PM, Stephan O, Colliex C, Trauth D. Aligned carbon nanotube arrays formed by cutting a polymer resin--nanotube composite. Science, 265, 1212 (1994). doi: 10.1126/science.265.5176.1212.

[3] Hong J, Park DW, Shim SE. A review on thermal conductivity of polymer composites using carbon-based fillers: carbon nanotubes and carbon fibers. Carbon Lett, 11, 347 (2010).

[4] Zhang J, Zou H, Qing Q, Yang Y, Li Q, Liu Z, Guo X, Du Z. Effect of chemical oxidation on the structure of single-walled carbon nanotubes. J Phys Chem B, 107, 3712 (2003). doi: 10.1021/ jp027500u.

[5] im KS, Rhee KY, Lee KH, Byun JH, Park SJ. Rheological behaviors and mechanical properties of graphite nanoplate/carbon nanotube-filled epoxy nanocomposites. J Ind Eng Chem, 16, 572 (2010). doi: 10.1016/j.jiec.2010.03.017.

[6] Zhang X, Zhang J, Wang R, Liu Z. Cationic surfactant directed polyaniline/CNT nanocables: synthesis, characterization, and enhanced electrical properties. Carbon, 42, 1455 (2004). doi: 10.1016/j.carbon.2004.01.003.

[7] Sahoo NG, Rana S, Cho JW, Li L, Chan SH. Polymer nanocomposites based on functionalized carbon nanotubes. Prog Polym Sci, 35, 837 (2010). doi: 10.1016/j.progpolymsci.2010.03.002.

[8] Spitalsky Z, Tasis D, Papagelis K, Galiotis C. Carbon nanotubepolymer composites: chemistry, processing, mechanical and electrical properties. Prog Polym Sci, 35, 357 (2010). doi: 10.1016/j. progpolymsci.2009.09.003.

[9] Kim KS, Park SJ. Influence of enhanced dispersity of chemically treated MWNTs on physical properties of MWNTs/PVDF films. Macromol Res, 18, 981 (2010).

[10] Guo P, Chen X, Gao X, Song H, Shen H. Fabrication and mechanical properties of well-dispersed multiwalled carbon nanotubes/ epoxy composites. Composites Sci Technol, 67, 3331 (2007). doi: 10.1016/j.compscitech.2007.03.026.

[11] Liu L, Etika KC, Liao KS, Hess LA, Bergbreiter DE, Grunlan JC. Comparison of covalently and noncovalently functionalized carbon nanotubes in epoxy. Macromol Rapid Commun, 30, 627 (2009). doi: 10.1002/marc.200800778.

[12] Spitalsky Z, Krontiras CA, Georga SN, Galiotis C. Effect of oxidation treatment of multiwalled carbon nanotubes on the mechanical and electrical properties of their epoxy composites. Compos, Part A: Appl Sci Manuf, 40, 778 (2009). doi: 10.1016/j.compositesa.2009.03.008.

[13] Bai JB, Allaoui A. Effect of the length and the aggregate size of MWNTs on the improvement efficiency of the mechanical and electrical properties of nanocomposites--experimental investigation. Compos, Part A: Appl Sci Manuf, 34, 689 (2003). doi: 10.1016/s1359-835x(03)00140-4.

[14] Yang M, Gao Y, Li H, Adronov A. Functionalization of multiwalled carbon nanotubes with polyamide 6 by anionic ring-opening polymerization. Carbon, 45, 2327 (2007). doi: 10.1016/j.carbon.2007.07.021.

[15] Gojny FH, Wichmann MHG, Fiedler B, Schulte K. Influence of different carbon nanotubes on the mechanical properties of epoxy matrix composites--a comparative study. Composites Sci Technol, 65, 2300 (2005). doi: 10.1016/j.compscitech.2005.04.021.

[16] Gong X, Liu J, Baskaran S, Voise RD, Young JS. Surfactant-assisted processing of carbon nanotube/polymer composites. Chem Mater, 12, 1049 (2000). doi: 10.1021/cm9906396.

[17] Miyagawa H, Drzal LT. Thermo-physical and impact properties of epoxy nanocomposites reinforced by single-wall carbon nanotubes. Polymer, 45, 5163 (2004). doi: 10.1016/j.polymer.2004.05.036.

[18] Kim KS, Park SJ. Influence of surface treatment of multi-walled carbon nanotubes on interfacial interaction of nanocomposites. Carbon Lett, 11, 102 (2010).

[19] Jung HT, Cho Y, Kim T, Kim TA, Park M. Preparation of amineepoxy adducts(AEA)/thin multiwalled carbon nanotubes (TWCNTs) composite particles using dry processes. Carbon Lett, 11, 107 (2010).

[20] Lee YS, Im JS, Yun SM, Nho YC, Kang PH, Jin H. X-ray photoelectron spectroscopic analysis of modified MWCNT and dynamic mechanical properties of e-beam cured epoxy resins with the MWCNT. Carbon Lett, 10, 314 (2009).

[21] Meincke O, Kaempfer D, Weickmann H, Friedrich C, Vathauer M, Warth H. Mechanical properties and electrical conductivity of carbon-nanotube filled polyamide- 6 and its blends with acrylonitrile/butadiene/styrene. Polymer, 45, 739 (2004). doi: 10.1016/j. polymer.2003.12.013.

[22] Gao J, Zhao B, Itkis ME, Bekyarova E, Hu H, Kranak V, Yu A, Haddon RC. Chemical engineering of the single-walled carbon nanotube-nylon 6 interface. J Am Chem Soc, 128, 7492 (2006). doi: 10.1021/ja057484p.

[23] Xia H, Wang Q, Qiu G. Polymer-encapsulated carbon nanotubes prepared through ultrasonically initiated in situ emulsion polymerization. Chem Mater, 15, 3879 (2003). doi: 10.1021/cm0341890.

[24] Gao J, Itkis ME, Yu A, Bekyarova E, Zhao B, Haddon RC. Continuous spinning of a single-walled carbon nanotube-nylon composite fiber. J Am Chem Soc, 127, 3847 (2005). doi: 10.1021/ja0446193.

[25] Zhao C, Hu G, Justice R, Schaefer DW, Zhang S, Yang M, Han CC. Synthesis and characterization of multi-walled carbon nanotubes reinforced polyamide 6 via in situ polymerization. Polymer, 46, 5125 (2005). doi: 10.1016/j.polymer.2005.04.065.

[26] Shao W, Wang Q, Wang F, Chen Y. The cutting of multi-walled carbon nanotubes and their strong interfacial interaction with polyamide 6 in the solid state. Carbon, 44, 2708 (2006). doi: 10.1016/j. carbon.2006.04.006

[27] Liu, Phang IY, Shen L, Chow SY, Zhang WD. Morphology and mechanical properties of multiwalled carbon nanotubes reinforced nylon-6 composites. Macromolecules, 37, 7214 (2004). doi: 10.1021/ ma049132t.

[28] Zhang WD, Shen L, Phang IY, Liu T. Carbon nanotubes reinforced nylon-6 composite prepared by simple melt-compounding. Macromolecules, 37, 256 (2003). doi: 10.1021/ma035594f.

[29] Chae HG, Sreekumar TV, Uchida T, Kumar S. A comparison of 
reinforcement efficiency of various types of carbon nanotubes in polyacrylonitrile fiber. Polymer, 46, 10925 (2005). doi: 10.1016/j. polymer.2005.08.092.

[30] Hou H, Ge JJ, Zeng J, Li Q, Reneker DH, Greiner A, Cheng SZD. Electrospun polyacrylonitrile nanofibers containing a high concentration of well-aligned multiwall carbon nanotubes. Chem Mater, 17, 967 (2005). doi: 10.1021/cm0484955.

[31] Chae HG, Minus ML, Kumar S. Oriented and exfoliated single wall carbon nanotubes in polyacrylonitrile. Polymer, 47, 3494 (2006). doi: 10.1016/j.polymer.2006.03.050.

[32] Fornes TD, Baur JW, Sabba Y, Thomas EL. Morphology and properties of melt-spun polycarbonate fibers containing singleand multi-wall carbon nanotubes. Polymer, 47, 1704 (2006). doi: 10.1016/j.polymer.2006.01.003.

[33] Singh S, Pei Y, Miller R, Sundararajan PR. Long-range, entangled carbon nanotube networks in polycarbonate. Adv Funct Mater, 13, 868 (2003). doi: 10.1002/adfm.200304411.

[34] Kim KH, Jo WH. A strategy for enhancement of mechanical and electrical properties of polycarbonate/multi-walled carbon nanotube composites. Carbon, 47, 1126 (2009). doi: 10.1016/j.carbon. 2008.12.043.

[35] Zou Y, Feng Y, Wang L, Liu X. Processing and properties of MWNT/HDPE composites. Carbon, 42, 271 (2004). doi: 10.1016/j. carbon.2003.10.028.

[36] Kanagaraj S, Varanda FR, Zhil'tsova TV, Oliveira MSA, Simoes JAO. Mechanical properties of high density polyethylene/carbon nanotube composites. Composites Sci Technol, 67, 3071 (2007). doi: 10.1016/j.compscitech.2007.04.024.

[37] Tang W, Santare MH, Advani SG. Melt processing and mechanical property characterization of multi-walled carbon nanotube/high density polyethylene (MWNT/HDPE) composite films. Carbon, 41, 2779 (2003). doi: 10.1016/s0008-6223(03)00387-7.

[38] Xiao KQ, Zhang LC, Zarudi I. Mechanical and rheological properties of carbon nanotube-reinforced polyethylene composites. Composites Sci Technol, 67, 177 (2007). doi: 10.1016/j.compscitech.2006.07.027.

[39] Tong X, Liu C, Cheng HM, Zhao H, Yang F, Zhang X. Surface modification of single-walled carbon nanotubes with polyethylene via in situ Ziegler-Natta polymerization. J Appl Polym Sci, 92, 3697 (2004). doi: 10.1002/app.20306.

[40] Gorrasi G, Sarno M, Di Bartolomeo A, Sannino D, Ciambelli P, Vittoria V. Incorporation of carbon nanotubes into polyethylene by high energy ball milling: Morphology and physical properties. J Polym Sci, Part B: Polym Phys, 45, 597 (2007). doi: 10.1002/ polb.21070.

[41] Bin Y, Kitanaka M, Zhu D, Matsuo M. Development of highly oriented polyethylene filled with aligned carbon nanotubes by gelation/crystallization from solutions. Macromolecules, 36, 6213 (2003). doi: 10.1021/ma0301956.

[42] Wang Y, Cheng R, Liang L, Wang Y. Study on the preparation and characterization of ultra-high molecular weight polyethylene-carbon nanotubes composite fiber. Composites Sci Technol, 65, 793 (2005). doi: 10.1016/j.compscitech.2004.10.012.

[43] Ruan SL, Gao P, Yang XG, Yu TX. Toughening high performance ultrahigh molecular weight polyethylene using multiwalled carbon nanotubes. Polymer, 44, 5643 (2003). doi: 10.1016/s00323861(03)00628-1.

[44] Ruan S, Gao P, Yu TX. Ultra-strong gel-spun UHMWPE fibers reinforced using multiwalled carbon nanotubes. Polymer, 47, 1604
(2006). doi: 10.1016/j.polymer.2006.01.020.

[45] Siochi EJ, Working DC, Park C, Lillehei PT, Rouse JH, Topping CC, Bhattacharyya AR, Kumar S. Melt processing of SWCNTpolyimide nanocomposite fibers. Compos, Part B: Eng, 35, 439 (2004). doi: 10.1016/j.compositesb.2003.09.007.

[46] Ogasawara T, Ishida Y, Ishikawa T, Yokota R. Characterization of multi-walled carbon nanotube/phenylethynyl terminated polyimide composites. Compos, Part A: Appl Sci Manuf, 35, 67 (2004). doi: 10.1016/j.compositesa.2003.09.003.

[47] Yu A, Hu H, Bekyarova E, Itkis ME, Gao J, Zhao B, Haddon RC. Incorporation of highly dispersed single-walled carbon nanotubes in a polyimide matrix. Composites Sci Technol, 66, 1190 (2006). doi: 10.1016/j.compscitech.2005.10.023.

[48] Liu T, Tong Y, Zhang WD. Preparation and characterization of carbon nanotube/polyetherimide nanocomposite films. Composites Sci Technol, 67, 406 (2007). doi: 10.1016/j.compscitech. 2006.09.007.

[49] Zhu BK, Xie SH, Xu ZK, Xu YY. Preparation and properties of the polyimide/multi-walled carbon nanotubes (MWNTs) nanocomposites. Composites Sci Technol, 66, 548 (2006). doi: 10.1016/j. compscitech.2005.05.038.

[50] So HH, Cho JW, Sahoo NG. Effect of carbon nanotubes on mechanical and electrical properties of polyimide/carbon nanotubes nanocomposites. Eur Polym J, 43, 3750 (2007). doi: 10.1016/j. eurpolymj.2007.06.025.

[51] Yuen SM, Ma CCM, Lin YY, Kuan HC. Preparation, morphology and properties of acid and amine modified multiwalled carbon nanotube/polyimide composite. Composites Sci Technol, 67, 2564 (2007). doi: 10.1016/j.compscitech.2006.12.006.

[52] Seo DW, Yoon WJ, Park SJ, Jo MC, Kim JS. The preparation of multiwalled CNT-PMMA nanocomposite. Carbon Lett, 7, 266 (2006).

[53] Jia Z, Wang Z, Xu C, Liang J, Wei B, Wu D, Zhu S. Study on poly(methyl methacrylate)/carbon nanotube composites. Mater Sci Eng, A, 271, 395 (1999). doi: 10.1016/s0921-5093(99)00263-4.

[54] Cooper CA, Ravich D, Lips D, Mayer J, Wagner HD. Distribution and alignment of carbon nanotubes and nanofibrils in a polymer matrix. Composites Sci Technol, 62, 1105 (2002). doi: 10.1016/ s0266-3538(02)00056-8.

[55] Kim KH, Jo WH. Improvement of tensile properties of poly(methyl methacrylate) by dispersing multi-walled carbon nanotubes functionalized with poly(3-hexylthiophene)-graft-poly(methyl methacrylate). Composites Sci Technol, 68, 2120 (2008). doi: 10.1016/j. compscitech.2008.03.008.

[56] Sabba Y, Thomas EL. High-concentration dispersion of singlewall carbon nanotubes. Macromolecules, 37, 4815 (2004). doi: 10.1021/ma049706u.

[57] Bae DY, Lee HS. Enhanced compatibility of PC/PMMA alloys by adding multiwall carbon nanotubes. Carbon Lett, 11, 83 (2010).

[58] Wang M, Pramoda KP, Goh SH. Enhancement of interfacial adhesion and dynamic mechanical properties of poly(methyl methacrylate)/multiwalled carbon nanotube composites with amine-terminated poly(ethylene oxide). Carbon, 44, 613 (2006). doi: 10.1016/j. carbon.2005.10.001.

[59] Velasco-Santos C, Martínez-Hernandez AL, Fisher FT, Ruoff R, Castano VM. Improvement of thermal and mechanical properties of carbon nanotube composites through chemical functionalization. Chem Mater, 15, 4470 (2003). doi: 10.1021/cm034243c.

[60] Park SJ, Cho MS, Lim ST, Choi HJ, Jhon MS. Synthesis and dispersion characteristics of multi-walled carbon nanotube composites 
with poly(methyl methacrylate) prepared by in-situ bulk polymerization. Macromol Rapid Commun, 24, 1070 (2003). doi: 10.1002/ marc. 200300089

[61] Manchado MAL, Valentini L, Biagiotti J, Kenny JM. Thermal and mechanical properties of single-walled carbon nanotubes-polypropylene composites prepared by melt processing. Carbon, 43, 1499 (2005). doi: 10.1016/j.carbon.2005.01.031.

[62] Kearns JC, Shambaugh RL. Polypropylene fibers reinforced with carbon nanotubes. J Appl Polym Sci, 86, 2079 (2002). doi: 10.1002/app.11160.

[63] McIntosh D, Khabashesku VN, Barrera EV. Benzoyl peroxide initiated in situ functionalization, processing, and mechanical properties of single-walled carbon nanotube-polypropylene composite fibers. J Phys Chem C, 111, 1592 (2007). doi: 10.1021/jp065399d.

[64] Chang TE, Jensen LR, Kisliuk A, Pipes RB, Pyrz R, Sokolov AP. Microscopic mechanism of reinforcement in single-wall carbon nanotube/polypropylene nanocomposite. Polymer, 46, 439 (2005). doi: 10.1016/j.polymer.2004.11.030.

[65] Zhao P, Wang K, Yang H, Zhang Q, Du R, Fu Q. Excellent tensile ductility in highly oriented injection-molded bars of polypropylene/carbon nanotubes composites. Polymer, 48, 5688 (2007). doi: 10.1016/j.polymer.2007.07.022.

[66] Grady BP, Pompeo F, Shambaugh RL, Resasco DE. Nucleation of polypropylene crystallization by single-walled carbon nanotubes. J Phys Chem B, 106, 5852 (2002). doi: 10.1021/jp014622y.

[67] Shim YS, Park SJ. Influence of glycidyl methacrylate grafted multiwalled carbon nanotubes on viscoelastic behaviors of polypropylene nanocomposites. Carbon Lett, 11, 311 (2010).

[68] Karevan M, Pucha RV, Bhuiyan MA, Kalaitzidou K. Effect of interphase modulus and nanofiller agglomeration on the tensile modulus of graphite nanoplatelets and carbon nanotube reinforced polypropylene nanocomposites. Carbon Lett, 11, 325 (2010).

[69] Safadi B, Andrews R, Grulke EA. Multiwalled carbon nanotube polymer composites: synthesis and characterization of thin films. J Appl Polym Sci, 84, 2660 (2002). doi: 10.1002/app.10436.

[70] Andrews R, Jacques D, Minot M, Rantell T. Fabrication of carbon multiwall nanotube/polymer composites by shear mixing. Macromolecular Materials and Engineering, 287, 395 (2002). doi: 10. 1002/1439-2054(20020601)287:6<395::aid-mame395>3.0.co;2-s.

[71] Xie L, Xu F, Qiu F, Lu H, Yang Y. Single-walled carbon nanotubes functionalized with high bonding density of polymer layers and enhanced mechanical properties of composites. Macromolecules, 40, 3296 (2007). doi: 10.1021/ma062103t.

[72] Xiong J, Zheng Z, Qin X, Li M, Li H, Wang X. The thermal and mechanical properties of a polyurethane/multi-walled carbon nanotube composite. Carbon, 44, 2701 (2006). doi: 10.1016/j.carbon.2006.04.005.

[73] Koerner H, Liu W, Alexander M, Mirau P, Dowty H, Vaia RA. Deformation-morphology correlations in electrically conductive carbon nanotube--thermoplastic polyurethane nanocomposites. Polymer, 46, 4405 (2005). doi: 10.1016/j.polymer.2005.02.025.

[74] Xu M, Zhang T, Gu B, Wu J, Chen Q. Synthesis and properties of novel polyurethane-urea/multiwalled carbon nanotube composites. Macromolecules, 39, 3540 (2006). doi: 10.1021/ma052265+.

[75] Sen R, Zhao B, Perea D, Itkis ME, Hu H, Love J, Bekyarova E, Haddon RC. Preparation of single-walled carbon nanotube reinforced polystyrene and polyurethane nanofibers and membranes by electrospinning. Nano Lett, 4, 459 (2004). doi: 10.1021/n1035135s.

[76] Chen W, Tao X. Self-organizing alignment of carbon nanotubes in thermoplastic polyurethane. Macromol Rapid Commun, 26, 1763 (2005). doi: 10.1002/marc.200500531.

[77] Kim YJ, Jang YK, Kim WN, Park M, Kim JK, Yoon HG. Electrical enhancement of polyurethane composites filled with multiwalled carbon nanotubes by controlling their dispersion and damage. Carbon Lett, 11, 96 (2010).

[78] Paiva MC, Zhou B, Fernando KAS, Lin Y, Kennedy JM, Sun YP. Mechanical and morphological characterization of polymer-carbon nanocomposites from functionalized carbon nanotubes. Carbon, 42, 2849 (2004). doi: 10.1016/j.carbon.2004.06.031.

[79] Ryan KP, Cadek M, Nicolosi V, Blond D, Ruether M, Armstrong G, Swan H, Fonseca A, Nagy JB, Maser WK, Blau WJ, Coleman JN. Carbon nanotubes for reinforcement of plastics? A case study with poly(vinyl alcohol). Composites Sci Technol, 67, 1640 (2007). doi: 10.1016/j.compscitech.2006.07.006

[80] Zhang X, Liu T, Sreekumar TV, Kumar S, Moore VC, Hauge RH, Smalley RE. Poly(vinyl alcohol)/SWNT composite film. Nano Lett, 3, 1285 (2003). doi: 10.1021/n1034336t.

[81] Cadek M, Coleman JN, Ryan KP, Nicolosi V, Bister G, Fonseca A, Nagy JB, Szostak K, Beguin F, Blau WJ. Reinforcement of polymers with carbon nanotubes: the role of nanotube surface area. Nano Lett, 4, 353 (2004). doi: 10.1021/n1035009o.

[82] Kim YY, Yun J, Lee YS, Kim HI. Electro-responsive transdermal drug release of MWCNT/PVA nanocomposite hydrogels. Carbon Lett, 11, 211 (2010).

[83] Shaffer MSP, Windle AH. Fabrication and characterization of carbon nanotube/poly(vinyl alcohol) composites. Adv Mater, 11, 937 (1999). doi: 10.1002/(sici)1521-4095(199908)11:11<937::aidadma937>3.0.co;2-9. 